\title{
PENGARUH CAMPURAN SAMPAH PLASTIK DENGAN KATALIS ALAM TERHADAP HASIL PRODUK PYROLISIS
}

\author{
Nuryosuwito ${ }^{1}$, Sudjito ${ }^{2}$, Widya Wijayanti ${ }^{2}$, Mega Nur Sasongko ${ }^{2}$ \\ 1. Universitas Nusantara PGRI Kediri Jawa Timur. \\ JI.KH. Achmad Dahlan No. 76, Mojoroto Kediri. \\ 2Jurusan Teknik Mesin, Universitas Brawijaya Malang. \\ JI.MT. Haryono 167, Malang 65145, Indonesia. \\ Email : nuryosuwito@ymail.com
}

\begin{abstract}
Currently, various methods have been developed to overcome the problems caused by garbage. Pyrolysis is one methode of waste processing which is considered to be prospective enough to be developed. It's because some advantages such as high conversion ratio and high energy content and potency as an alternative fuel in the future. Therefore, in this paper characteristics of pyrolysis will be studied. The waste materials used are catalyst and plastic waste. The resultant products of the pyrolysis process analyzed by Gas Chromatography / Mass Spectroscopy (GC / MS), while the thermal decomposition analysis was performed using Thermo Gravimetric Analysis (TGA). The results of pyrolysis process in isothermal conditions of a single component and a mixture of plastic waste and natural catalyst show that the final temperature of pyrolysis and the rate of heating affects to the distribution of pyrolysis products for all samples. As pyrolytic temperatures increase, liquid and gas products increase, while solid products tend to decrease. In the temperature range of $300^{\circ} \mathrm{C}, 400^{\circ} \mathrm{C}, 500^{\circ} \mathrm{C}, 600^{\circ} \mathrm{C}$ pyrolysis temperature with a heating rate of $100^{\circ} \mathrm{C} / \mathrm{min}$ is the ideal temperature for obtaining the pyrolysis product of the liquid fraction and and the maximum gas fraction for all waste types studied.
\end{abstract}

Keywords: Pyrolysis, Catalysts, Plastic waste, Pyrolysis products.

\section{PENDAHULUAN}

Permasalahan sampah menjadi semakin serius seiring dengan meningkatnya produksi sampah dari tahun ke tahun. Berdasarkan data Bank Dunia, jumlah sampah padat di kota-kota dunia akan terus naik sebesar $70 \%$ tahun ini hingga tahun 2025 , dari 1,3 miliar ton per tahun menjadi 2,2 miliar ton per tahun. Mayoritas kenaikan terjadi di kotakota di negara berkembang. Di Indonesia, data Bank Dunia menyebutkan, produksi Sampah padat secara nasional mencapai 151.921 ton per hari. Hal ini berarti, setiap penduduk Indonesia membuang sampah padat rata-rata $0,85 \mathrm{~kg}$ per hari. Data yang sama juga menyebutkan, dari total sampah yang dihasilkan secara nasional, hanya $80 \%$ yang berhasil dikumpulkan, sisanya terbuang mencemari lingkungan [1]

Berbagai upaya telah dilakukan untuk mengatasi permasalahan yang ditimbulkan oleh sampah khsusnya sampah jenis rubbish (sampah yang tidak dapat terurai oleh mikroorganisme). Proses pirolisis merupakan salah satu alternatif pengolahan sampah kota yang dipandang cukup prospektif untuk dikembangkan karena memiliki beberapa keuntungan di antaranya; memiliki rasio konversi yang tinggi, produknya memiliki kandungan energi yang tinggi, produk yang dihasilkan dapat ditingkatkan menjadi bahan dasar keperluan lain, serta pengontrolan proses yang lebih mudah bila dibandingkan dengan proses insinerasi [2]

Beberapa penelitian yang berkaitan dengan proses pirolisis sampah jenis rubbish telah banyak dilakukan, hanya saja melibatkan kondisi operasi yang relatif terbatas sehingga variasi produk-produk hasil pirolisis yang diperoleh memiliki jangkauan yang terbatas. Hal ini tentu saja menyulitkan dalam melakukan optimasi proses pirolisis dan 
karakterisasi produk hasil pirolisis sebagai bahan bakar alternatif karena keterbatasan data-data hasil pirolisis. Di samping itu, penelitian pirolisis campuran Pirolisis adalah proses dekomposisi bahan organik dan polimer dengan memanaskan bahan tersebut tanpa oksigen untuk menghasilkan produk-produk dengan berat molekul yang lebih rendah[3]. Pada proses pirolisis akan terjadi proses pengeringan yaitu menguapnya kadar air (moisture content) dan devolatilisasi yaitu zat yang mudah menguap (volatile matter) ke luar dari dalam bahan. Produk utama dari pirolisis adalah residu karbon (char), minyak pirolisis (pyrolitic oil) atau tar dan gas (pyrogas). Proses pirolisis ini dimulai temperatur sekitar $250^{\circ} \mathrm{C}$ dan berakhir pada temperatur $550^{\circ} \mathrm{C}$. Kehadiran katalis pada proses ini akan menghasilkan minyak ringan (lights oil) dengan peningkatan yang drastis dalam konsentrasi rantai aromatik tunggal [4].

Tabel 1. Nilai kalor plastik dan bahan lainnya.

\begin{tabular}{lc}
\hline Material & Nilai Kalor (MJ/kg) \\
\hline Polyethylene & 46,3 \\
Polypropylene & 46,4 \\
Polyvinyl chloride & 18,0 \\
Polystyrene & 41,4 \\
Coal & 24,3 \\
Petrol & 44,0 \\
Diesel & 43,0 \\
Heavy fuel oil & 41,1 \\
Light fuel oil & 41.9 \\
LPG & 46,1 \\
Kerosene & 43,4 \\
\hline
\end{tabular}

Pengolahan sampah plastik mempunyai prospek yang baik sebagai bahan bakar karena bahan plastik mempunyai nilai kalor yang cukup tinggi (tabel 1). Penelitian awal tentang dekomposisi pada pyrolysis meneliti tentang efek dari laju pemanasan, temperatur dan waktu [5]. Hasil penelitian ini menyimpulkan bahwa 95\% selulosa terdekomposisi pada temperatur antara $500^{\circ} \mathrm{C}$ dan $750^{\circ} \mathrm{C}$ laju pemanasannya adalah $1000^{\circ} \mathrm{C} / \mathrm{s}$. Setelah $750^{\circ} \mathrm{C}$, hasil dari char menurun. Juga diketahui bahwa hasil dari tar yang terjadi sebesar $83 \%$ pada suhu $400^{\circ} \mathrm{C}$ dan menurun menjadi $49 \%$ pada suhu $1000^{\circ} \mathrm{C}$. Ini dikarenakan adanya reaksi tar sekunder yang terjadi pada sampah plastik dan ban bekas masih jarang dilakukan sehingga keterseidaan literaturnya masih sangat terbatas.

temperatur yang lebih tinggi. Diatas suhu $750^{\circ} \mathrm{C}$ hasil dari char menurun dari $6 \%$ menjadi $3 \%$. Ketika terjadi kenaikan temperatur di atas $900^{\circ} \mathrm{C}$ hasil dari char kembali naik menjadi $4 \%$ Yang mengindikasikan pada temperatur di atas $900^{\circ} \mathrm{C}$ reaksi repolimerisasi terjadi dan menghasilkan kenaikan pada char. Hasil dari pemecahan selulosa pada $300-600^{\circ} \mathrm{C}$ kebanyakan menghasilkan senyawa oxygenated seperti acetaldehyde. Seiring dengan kenaikan temperatur yang melebihi $600^{\circ} \mathrm{C}$ menghasilkan gas hidrokarbon yang meningkat, hal ini mengindikasikan adanya reaksi tar sekunder. Kemudian seiring kenaikan waktu tinggal padatan, jumlah tar yang dihasilkan meningkat sampai dengan suhu $800^{\circ} \mathrm{C}[6]$.

Lebih dari temperatur ini waktu tinggal padatan tidak memiliki pengaruh yang berarti. Sampai dengan temperatur $750^{\circ} \mathrm{C}$ dan waktu tinggal yang pendek, meningkatkan laju pemanasan akan menurunkan tar yang dihasilkan, karena pada laju pemanasan yang tinggi dan waktu tinggal yang pendek akan menyebabkan devolatilisasi tidak terjadi sempurna dan produk tar yang dihasilkan akan terurai cepat ketika mereka terbentuk. [7]. Sebuah penelitian terdahulu melakukan penelitian dengan laju pemanasan antara $5^{\circ} \mathrm{C} / \mathrm{min}$ dan $80^{\circ} \mathrm{C} / \mathrm{min}$ dengan temperatur $300^{\circ} \mathrm{C}$ dan $750^{\circ} \mathrm{C}$. Diteliti bahwa ketika laju pemanasan bertambah maka hasil dari char akan menurun. Gas utama yang dihasilkan pada temperatur antara $200^{\circ} \mathrm{C}$ dan $400^{\circ} \mathrm{C}$ adalah $\mathrm{CO}$ dan $\mathrm{CO}_{2}$ namun pada temperatur yang lebih tinggi konsentrasi yang rendah dari gas hidrokarbon juga ditemukan. Ketika laju pemanasan dinaikan jumlah dari gas seperti $\mathrm{CO}, \mathrm{CO} 2, \mathrm{CH} 4$ dan lainnya meningkat[8].

Pyrolysis bahan plastik polyethylene dengan variasi temperatur operasi antara 450-500 ${ }^{\circ} \mathrm{C}$, serta variasi massa dan jenis katalis Zeolite $Y$ dan Natural Zeolite. Selain itu variasi juga dilakukan dengan pencampuran bahan PE tersebut dengan jenis Polystyrene, Polypropylene, Polyethylene Terephthalate, dan Other. Karakteristik char diketahui melalui proximate test meliputi moisture content, ash, 
volatile matter, dan fixed carbon, nilai kalor diuji melalui bomb calorimeter. Kualitas pembakaran diuji dalam furnace dengan temperatur dinding $\pm 230^{\circ} \mathrm{C}$ dan aliran udara konstan 0,7 m/s, serta diukur kadar emisinya. Permasalahannya adalah dalam aplikasi diketahui bahwa pembakaran briket tidak optimal, ditandai periode pemanasan yang lama, serta kadar CO yang bervariasi. Oleh karena itu perlu dilakukan upaya optimasi kualitas pembakaran yang akan dianalisis melalui pengujian ultimate dan efek porositas. Parameter yang berpengaruh pada kecepatan reaksi pyrolysis mempunyai hubungan yang sangat kompleks, sehingga model matematis persamaan kecepatan reaksi pyrolysis yang diformulasikan oleh setiap peneliti selalu menunjukkan rumusan empiris yang berbeda.

Fakto-faktor atau kondisi yang mempengaruhi proses pirolisis

\section{Waktu}

Waktu berpengaruh pada produk yang akan dihasilkan karena semakin lama waktu proses pyrolysis berlangsung, produk yang dihasilkannya (residu padat, tar, dan gas) makin naik. Kenaikan itu sebatas sampai dengan waktu tak hingga $(\tau)$ yaitu waktu yang diperlukan sampai dengan hasil padatan residu, tar, dan gas mencapai konstan. Nilai $\tau$ dihitung sejak proses isotermal berlangsung. Tetapi jika melebihi waktu optimal maka karbon akan teroksidasi oleh oksigen (terbakar), menjadi karbondioksida dan abu. Untuk itu pada proses pirolisis penentuan waktu optimal sangatlah penting. Dengan mengambil anggapan bahwa reaksi dekomposisi berlangsung secara progresif atau seragam pada seluruh partikel, maka persamaan kecepatan reaksi yang dinyatakan dalam fraksi massa per satuan waktu adalah $\mathrm{dw} / \mathrm{dt}=-\mathrm{k}\left(\mathrm{w}-\mathrm{w}_{\infty}\right)^{\mathrm{n}}$ dimana :

$$
\begin{aligned}
& \mathrm{w}=\text { fraksi massa sampah, yang } \\
& \text { dinyatakan dengan } \mathrm{w}=\mathrm{m}_{\mathrm{t}} / \mathrm{m}_{\mathrm{to}} \\
& \mathrm{W}_{\infty}=\text { fraksi residu padat pada saat } \mathrm{t}=\infty \text {, } \\
& \text { yang dinyatakan dengan } \\
& \mathrm{w}_{\infty}=\mathrm{m}_{\infty} / \mathrm{m}_{\mathrm{to}} \\
& \mathrm{m}_{\mathrm{to}}=\text { massa umpan saat awal pada suhu } \\
& \text { isotermal ( } \mathrm{gr} \text { ) } \\
& \mathrm{m}_{\mathrm{t}}=\text { massa residu padat setiap saat }(\mathrm{gr})
\end{aligned}
$$

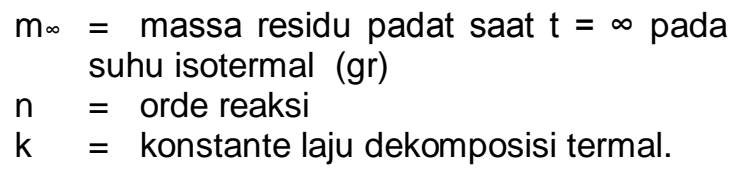

Pada saat $(\mathrm{t})$, fraksi volatile matter yang terdekomposisi mencapai $\left(\mathrm{x}_{\mathbf{s}}\right)$, oleh Liliedahl dan Sjostrom (1994) didefinisikan sebagai devolatilization degree yang nilainya adalah : $\mathrm{x}_{\mathbf{s}}=\left[\mathrm{m}_{\mathrm{to}}-\mathrm{m}_{\mathrm{t}}\right] /\left[\mathrm{m}_{\mathrm{to}}-\mathrm{m}_{\square}\right]$

\section{Temperatur}

Temperatur sangat mempengaruhi produk yang dihasilkan karena sesuai dengan persamaan Arhenius, semakin tinggi temperatur, nilai konstanta dekomposisi termal makin besar. Akibatnya laju pyrolysis bertambah dan konversi naik. Pada proses pyrolysis suhu rendah $(<700)$ dimulai pada suhu antara $225-275^{\circ} \mathrm{C}[9]$. Untuk itu, variasi percobaan agar reaksi pyrolysis benar - benar telah terjadi maka diambil kisaran suhu yang perlu dipelajari, yaitu $300-500^{\circ} \mathrm{C}$. Berdasarkan teorema Arrhenius hubungan konstanta persamaan reaksi dengan suhu absolut, adalah:

$k=k_{0} \cdot e^{-(E / R T)}$

Dengan,

$\mathrm{k}=$ Konstanta kecepatan reaksi dekomposisi termal

$\mathrm{k}_{0}=$ Faktor tumbukan (faktor frekuensi)

$\mathrm{E}=$ Energi aktivasi (kal/gr.mol)

$\mathrm{T}=$ Suhu absolut $\left({ }^{\circ} \mathrm{K}\right)$

$\mathrm{R}=$ Tetapan gas $\left(1,987 \mathrm{kal} / \mathrm{gr} \cdot \mathrm{mol}{ }^{0} \mathrm{~K}\right)$

maka persamaan (1) dapat dinyatakan dengan

$d w / d t=-k_{0} e^{-E / R T}\left(w-w_{\square}\right)^{n}$

jika kecepatan reaksi (4) mengikuti persamaan reaksi orde satu, maka

$d w / d t=-k_{0} e^{-E / R T}\left(w-w_{\square}\right)$

Pada proses isotermal integrasi persamaan (5) dengan keadaan batas antara $\mathrm{t}=\mathrm{t}_{1}$ sampai dengan $\mathrm{t}=\mathrm{t}_{2}$, diperoleh

$\ln \left(W_{1}-W_{\infty}\right)-\ln \left(W_{2}-W_{\infty}\right)$

$=k_{0} e^{-E / R T}\left(t_{2}-t_{1}\right)$

Dengan mengartikan kecepatan reaksi sama dengan, kecepatan massa pembentukan hasil 
(g/menit) per total massa yang dapat $m_{h o}=$ massa hasil pada saat $t=0$

terdevolatilisasi $\left(\mathrm{m}_{\mathrm{T}}\right)$, maka diperoleh :

$$
\begin{aligned}
& r_{h}=\left[\frac{1}{m_{t o}-m_{\infty}}\right] \frac{d m_{h}}{d t} \\
& r_{h}=k_{h} \frac{m_{h}-m_{h \infty}}{m_{t o}-m_{\infty}} \\
& {\left[\frac{1}{m_{t o}-m_{\infty}}\right] \frac{d m_{h}}{d t}=k_{h} \frac{m_{h}-m_{h \infty}}{m_{t o}-m_{\infty}}}
\end{aligned}
$$

Dengan,

$$
\begin{aligned}
& \mathrm{rh}_{\mathrm{h}} \quad=\text { kecepatan reaksi pembentukan hasil } \\
& \mathrm{k}_{\mathrm{h}}=\text { konstanta kecepatan pembentukan }
\end{aligned}
$$

$\mathrm{m}_{\mathrm{n} \infty}=$ massa hasil saat $\mathrm{t}=\tau$ pada suhu isotermal

Penyelesaian persamaan (7) akan diperoleh :

$\ln \left(m_{h \infty}-m_{h}\right)=\ln \left(m_{h \infty}-m_{h o}\right)-k_{h} . t$

Penerapan persamaan (8) jika digunakan untuk menentukan konstanta laju

\begin{tabular}{|c|c|c|}
\hline $\begin{array}{l}\text { No. } \\
\text { Kode }\end{array}$ & Jenis Plastik & Penggunaan \\
\hline 1 & $\begin{array}{l}\text { PET (polyethylene } \\
\text { terephthalate) }\end{array}$ & $\begin{array}{l}\text { botol kemasan air mineral, botol minyak goreng, } \\
\text { jus, botol sambal, botol obat, dan botol kosmetik }\end{array}$ \\
\hline 2 & $\begin{array}{l}\text { HDPE (High-density } \\
\text { Polyethylene) }\end{array}$ & $\begin{array}{l}\text { botol obat, botol susu cai } \\
\text { botol kosmetik }\end{array}$ \\
\hline 3 & $\begin{array}{l}\text { PVC (Polyvinyl } \\
\text { Chloride) }\end{array}$ & $\begin{array}{l}\text { pipa selang air, pipa bangunan, mainan, taplak } \\
\text { meja dari plastik, botol shampo, dan botol sambal. }\end{array}$ \\
\hline 4 & $\begin{array}{l}\text { LDPE (Low-density } \\
\text { Polyethylene) }\end{array}$ & $\begin{array}{l}\text { kantong kresek, tutup plastik, plastik } \\
\text { pembungkus daging beku, dan berbagai macam } \\
\text { plastik tipis lainnva. }\end{array}$ \\
\hline 5 & $\begin{array}{l}\text { PP (Polypropylene } \\
\text { atau Polypropene) }\end{array}$ & $\begin{array}{l}\text { cup plastik, tutup botol dari plastik, mainan } \\
\text { anak, dan margarine }\end{array}$ \\
\hline 6 & PS (Polystyrene) & $\begin{array}{l}\text { kotak } C D \text {, sendok dan garpu plastik, gelas plastik, } \\
\text { atau tempat makanan dari styrofoam, dan tempat } \\
\text { makan plastik transparan }\end{array}$ \\
\hline 7 & $\begin{array}{l}\text { Other }(O), \text { jenis } \\
\text { plastik lainnya selair } \\
\text { dari no. } 1 \text { hingga } 6\end{array}$ & $\begin{array}{l}\text { botol susu bayi, plastik kemasan, gallon air } \\
\text { nminum, suku cadang mobil, alat-alat rumah } \\
\text { tangga, komputer, alat-alat elektronik, sikat gigi, } \\
\text { dan mainan lego }\end{array}$ \\
\hline
\end{tabular}
pembentukan tar (pyrolytic oil) dapat dituliskan :

$\ln \left(m_{v \infty}-m_{v}\right)=\ln \left(m_{v \infty}-m_{v o}\right)-k_{v} . t$

Dengan,

$\mathrm{kh}=$ konstanta laju reaksi pembentukan tar

$\mathrm{m}_{\mathrm{v}}=$ massa hasil tar pada setiap saat $\mathrm{t}=\mathrm{t}$

$\mathrm{m}_{\mathrm{vo}}=$ massa hasil tar pada saat $\mathrm{t}=0$

$\mathrm{m}_{\mathrm{v} \infty}=$ massa hasil tar pada saat $\mathrm{t}=\tau$

Tabel 2. Jenis plastik, kode dan penggunaannya

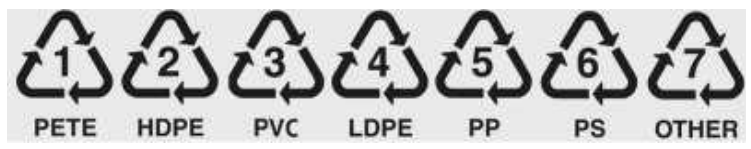

Gambar 1. Nomor kode plastik 
Berdasarkan sifat kedua kelompok plastik di atas, thermo plastik adalah jenis yang memungkinkan untuk didaur ulang. Jenis plastik yang dapat didaur ulang diberi kode berupa nomor untuk memudahkan dalam mengidentifikasi dan penggunaannya (lihat Tabel 2 dan Gambar 1). Selain itu data temperatur transisi dan temperatur lebur plastik (Tabel 3) dibutuhkan untuk menentukan parameter temperatur yang tepat saat proses pyrolisis.

Tabel 3. Data temperatur transisi dan temperatur lebur plastik

\begin{tabular}{lccc}
\hline $\begin{array}{c}\text { Jenis } \\
\text { Bahan }\end{array}$ & $\begin{array}{c}\mathbf{T m} \\
\left({ }^{\circ} \mathbf{C}\right)\end{array}$ & $\begin{array}{c}\mathbf{T g} \\
\left({ }^{\circ} \mathbf{C}\right)\end{array}$ & $\begin{array}{c}\text { Temperatur } \\
\text { kerja maks. } \\
\left({ }^{\circ} \mathbf{C}\right)\end{array}$ \\
\hline PP & 168 & 5 & 80 \\
HDPE & 134 & -110 & 82 \\
LDPE & 330 & -115 & Jenis \\
PA & 260 & 50 & PP \\
PET & 250 & 70 & HDPE \\
ABS & & 110 & LDPE \\
PS & & 90 & PA \\
PMMA & & 100 & PET \\
PC & & 150 & ABS \\
PVC & & 90 & PS \\
\hline
\end{tabular}

\section{METODOLOGI PENELITIAN}

Penelitian ini bertujuan untuk mengkaj dan mengoptimasi proses pirolisis campuran katalis dan sampah plastik dalam berbagai variasi campuran dan kondisi operasi. Optimasi dilakukan untuk mengetahui produkproduk hasil pirolisis, khususnya yang berbentuk cair dan gas yang dapat memenuhi persyaratan teknis sebagai bahan bakar alternatif yang telah ditetapkan. Pada penelitian selanjutnya akan dilakukan uji kemampuan produk-produk hasil pirolisis yang dapat memenuhi persyaratan teknis sebagai bahan bakar alternatif yang telah ditetapkan tersebut, yang meliputi uji pembakaran secara atmosferik dan pembakaran bertekanan di dalam silinder motor bakar.
Instalasi Peralatan Pengujian

Instalasi peralatan pengujian disusun seperti tampak pada gambar 4. Instalasi peralatan pengujian ini diadoptasi dari penelitiaan terdahulu [10], yang terdiri dari atas tungku pemanas yang dilengkapi dengan thermocontroller dengan pembacaan temperatur sampai dengan $1000^{\circ} \mathrm{C}$. Reaktor untuk proses pyrolysis berdiameter $96 \mathrm{~mm}$ tinggi $500 \mathrm{~mm}$ yang diletakkan pada sebuah furnace yang berdiameter dalam $104 \mathrm{~mm}$ dengan tinggi $490 \mathrm{~mm}$ dan dililiti elemen pemanas dengan panjang bentangan 12 meter au setinggi $15 \mathrm{~cm}$ dari dasar furnace. Pada bagian atas tabung reaktor terdapat saluran untuk mengalirkan gas hasil pyrolysis ke sistem pendingin. Pengurangan massa sampel yang terjadi selama proses pyrolysis, dilakukan dengan membuat lobang berdiameter $5 \mathrm{~mm}$ untuk peletakan kawat untuk menggantungkan tempat peletakan sampel ke timbangan digital. Tempat peletakan sampel berupa silinder berdiameter $8 \mathrm{~cm}$ dan tinggi $16 \mathrm{~cm}$ yang terbuat dari kawat strimin.

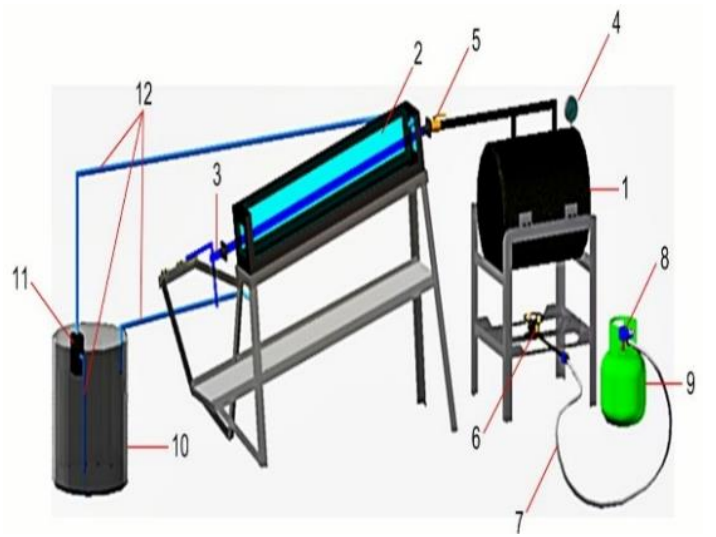

Gambar 4. Instalasi Peralatan Pengujian

Keterangan gambar :

1. (furnace)

2. Condenser.

3. Output pirolisis

4. Manometer

5. Valve

6. Gas stove

7. Selang gas

8. Regulator

9. Tabung

10. Water reservoir

11. Cooling water pump (Condenser.)

12.Cooling pipeln Installation drawing equipment 
Pada gambar Instalasi Peralatan Pengujian di atas terdapat pipa saluran dan pipa tersebut akan dilalui zat cair hasil pyrolysis.

\section{HASIL DAN PEMBAHASAN}

Hasil pyrolisis sampel sampah campuran katalis dan sampah plastik pada berbagai laju pemanasan dapat dilihat pada tabel 5 , tabel 6 , dan tabel 7 .

Tabel 5. Campuran $10 \%$ katalis dan $50 \mathrm{PL}$

\begin{tabular}{|c|c|c|c|}
\hline \multirow[t]{2}{*}{$\begin{array}{l}\text { Temperatur } \\
\text { Pirolisis } \\
\left({ }^{\circ} \mathrm{C}\right)\end{array}$} & \multicolumn{3}{|c|}{$\begin{array}{c}\text { Campuran } 10 \% \text { katalis dan } \\
50 \% \mathrm{PL} \\
\text { Laju pemanasan } 10^{\circ} \mathrm{C} / \text { menit }\end{array}$} \\
\hline & Char (\%) & Tar (\%) & Gas (\%) \\
\hline 400 & 16,8 & 44,6 & 36,9 \\
\hline 500 & 13,5 & 45,4 & 39,7 \\
\hline 600 & 12,2 & 46,8 & 40,6 \\
\hline
\end{tabular}

Tabel 6. Campuran $10 \%$ kataslis dan $50 \mathrm{PL}$ Temperatur Campuran 10\% katalis dan Pirolisis $\left({ }^{\circ} \mathrm{C}\right)$ $50 \% \mathrm{PL}$

Laju pemanasan $15^{\circ} \mathrm{C} /$ menit Char (\%) Tar (\%) Gas (\%)

\begin{tabular}{llll}
\hline 400 & 17,2 & 44,8 & 35,7 \\
500 & 14,3 & 45,2 & 38,6 \\
600 & 12,5 & 46,6 & 40,3 \\
\hline
\end{tabular}

Tabel 7. Campuran $10 \%$ kataslis dan $50 \mathrm{PL}$ Temperatur Campuran 10\% katalis dan Pyrolisis $\left({ }^{\circ} \mathrm{C}\right)$ $50 \% \mathrm{PL}$

Laju pemanasan $20^{\circ} \mathrm{C} /$ menit Char (\%) Tar (\%) Gas (\%)

$\begin{array}{llll}400 & 18,6 & 45,7 & 34,6 \\ 500 & 14,8 & 46,4 & 37,4 \\ 600 & 11,2 & 47,8 & 39,7\end{array}$

Dalam penelitian ini, campuran yang digunakan tetap yakni $10 \%$ katalis dan $50 \%$ plastik. Sedangkan variasi yang diberikan berupa temperatur pirolisis dan laju pemanasan. Hasil penelitian menunjukkan bahwa peningkatan temperatur pirolisis menyebabkan penurunan persentase Char, dan peningkatan persentase Tar dan Gas. Sedangkan peningkatan laju pemanasan menyebabkan produk berupa Char dan Tar meningkat, sedangkan Gas mengalami penurunan.

\section{KESIMPULAN}

Dari hasil analsis yang telah dilakukan, maka dapat disimpulkan hal-hal sebagai berikut; Produk pyrolisis fraksi cair maksimum diperoleh pada campuran $10 \%$ Plastik dan $50 \%$ katalis pada temperatur $600^{\circ} \mathrm{C}$ laju pemanasan $20^{\circ} \mathrm{C} /$ menit, sementara produk pyrolisis fraksi gas diperoleh pada campuran $20 \%$ katalis dan $50 \%$ sampah plastik pada temperatur $600^{\circ} \mathrm{C}$ laju pemanasan $20^{\circ} \mathrm{C} /$ menit.

\section{DAFTAR PUSTAKA}

[1] Borsodi, N., Miskolczi, N., Angyal, A., Bartha,L.,Kohán,J.,dan Lengyel,A., 2011, Hydrocarbonsobtained bypyrolysis of contaminated waste plastics, 45 th International Petroleum Conference, Bratislava, Slovak Republic.

[2] Casson,A.The HesitantBoom: Indonesia Õs OilPalmSub-Sector in an Era of Economic Crisis and Political Change, Occasional Paper No.29,June2000,Center for International Forestry Research

[3] Das,S.danPande, S.,2007,Pyrolysis and Catalytic Cracking of Municipal Plastic Waste for Recovery of Gasoline Range Hydrocarbons, Thesis, Chemical Engineering Department National Institute of Technology Rourkela

[4] H. Park, et al., "Pyrolysis Characteristics of Oriental WhiteOak: Kinetic Studyand Fast Pyrolysis in a Fluid- zed Bed withan Improved

Reaction System,"FuelProcessingTechnology, Vol.90, No. 2,2009,pp.186-195.

[5] J.Yang, R.Miranda, and C.Roy. "Using the DTG curve fitting method to determine the apparent kinetic parameters of thermal decomposition of polymers".

Polymer DegradationandStability,vol 73,pp.455461,2001. 
[6] Jones, D.L et all; Biochar-Mediated changes in soilquality and plant growth in a three year fiel dtrial. SoilBiol.Biochem.2012,45 113-124.

[7] Jones, S.B.et all. Production of Gasoline and Diesel from Biomass via Fast Pyrolysis, Hydrotreating and Hydrocracking: A Design Case; Report No.PNNL-18284;U.S.Department of Energy: Springfield, VA, USA, Jurnal Hasil Penelitian Kimia danTeknologi, ISSN0216-163X,Vol 1,USB,Solo

[8] K.Panda, R.K.Singhand D.K. Mishra."Thermolysis of waste plastics to liquid fuel suitable method for plastic waste management and manufacture of value added products-A world prospective".

Renewable\&SustainableEnergyReviews, vol.14,pp.233-248,2010.

[9] Panda, A.K., 2011, Studies on Process Optimization for Production of Liquid Fuels from Waste Plastics, Thesis, Chemical Engineering Department National Instituteof Technology Rourkela.
[10] Sarker,

Rahman,M.S.,dan M.,Rashid,

2012, Envirnmentally

Molla,

M.M., DensityWastePlastic

Harmfullow Environmental Protection, 2012, 3, 700 708.

[11] Tamilkolundu,S.

And Murugesan,C.,2012, The Evaluation of blend of Waste PlasticOil-Dieselfuel foruseas alternate fuel fortransportation, 2nd InternationalConference on Chemical, Ecology andEnvironmentalSciences (ICCEES'2012)SingaporeApril28-29, 2012

[12] Wahyudi,I.,2001.Pemanfaatan Blotong Menjadi Bahan Bakar Cair Dan Arang Dengan Proses Pirolisis. Jurusan Teknik Lingkungan FT SP UP "Veteran" Jatim 